\title{
FERRUGEM EM FRAMBOESA NO ESTADO DE SANTA CATARINA ${ }^{1}$ \\ RICARDO TREZZI CASA ${ }^{2}$, PAULO ROBERTO KUHNEM JUNIOR ${ }^{3}$, JONATHA MARCEL BOLZAN ${ }^{4}$, AMAURI BOGO², AIKE ANNELIESE KRETZSCHMAR ${ }^{2}$, LEO RUFATO ${ }^{2}$, TIAGO AFONSO DE MACEDO ${ }^{4}$
}

RESUMO - Folhas e frutos de framboesa (Rubus idaeus L.) da cultivar Batum coletados de plantas do pomar do Centro de Ciências Agroveterinárias, CAV, município de Lages-SC, apresentando pústulas de ferrugem, foram encaminhados para análise no Laboratório de Fitopatologia do CAV. A diagnose indireta indicou a presença de pústulas com uma massa de esporos de cor amarela na face abaxial das folhas e superfície dos frutos. No exame ao microscópio, observou-se urédia e urediniósporos pequenos, obovados ou elipsoides, medindo 12,5-17,5 x 15,0-30,0 $\mu \mathrm{m}$ sobre a epiderme da folha e frutos, sem a presença de télias. Suspensão de urediniósporos (50.000 esporos $\mathrm{mL}^{-1}$ ) em água esterilizada foi pulverizada em folhas destacadas da mesma cultivar, mantidas por $24 \mathrm{~h}$ no escuro e $12 \mathrm{~h}$ de fotoperíodo em câmara úmida a $20^{\circ} \mathrm{C}$. Folhas-controle foram pulverizadas com água esterilizada. Após 10 dias, detectaram-se urédias contendo urediniósporos na face abaxial das folhas, cujas características morfológicas e mensuração dos urediniósporos, sintomas e patogenicidade permitiram a identificação do agente causal como sendo Pucciniastrum americanum (Farl.) Arthur pela primeira vez no Estado de Santa Catarina.

Termos para Indexação: diagnose, fungo, ocorrência, Pucciniastrum americanum, Rubus idaeus.

\section{RED RASPBERRY RUST IN THE STATE OF SANTA CATARINA}

\begin{abstract}
Leaves and fruits of red raspberry (Rubus idaeus L.) of the cultivar Batum collected from the Agroveterinary Science Center - CAV orchard in Lages, SC, presenting rust pustules were analyzed in the CAV Plant Pathology Laboratory. Indirect diagnosis indicated in the abaxial side of the infected leaves and fruits surface pustules filled with masses of yellow spores. Under microscope exam, small, obovate or elliptical and averaged 12,5-17,5 x 15,0-30,0 $\mu \mathrm{m}$ uredia and urediniospores become evident in leaves and fruit surface. Telia were not observed. Urediniopores $\left(50.000\right.$ spores $\left.\mathrm{mL}^{-1}\right)$ were suspended in sterile water and sprayed onto same cultivar leaves that were maintained in a darkened mist chamber at $20^{\circ} \mathrm{C}$ for $24 \mathrm{~h}$ and transferred to $20^{\circ} \mathrm{C}$ and $12 \mathrm{~h}$ light cycle chamber. Control leaves received sterile water only. After 10 days, sporulating uredia with urediniospores were produced on abaxial leaves and according to morphological characteristic of urediniopores, symptoms and pathogenicity; this is the first report of Pucciniastrum americanum (Farl.) Arthur in the state of Santa Catarina, Brazil.
\end{abstract}

Index terms: diagnosis, fungi, occurrence, Pucciniastrum americanum, Rubus idaeus.

${ }^{1}$ (Trabalho 191-09). Recebido em: 14-08-2009. Aceito para publicação em: 07-12-2009.

${ }^{2}$ Dr. Professores do Departamento de Agronomia, Centro de Ciências Agroveterinárias (CAV) Universidade do Estado de Santa Catarina (UDESC), Lages-SC. E-mail: a2rtc@cav.udesc.br; a2ab@cav.udesc.br; a2aak@cav.udesc.br; a21r@cav.udesc.br. Bolsistas de Produtividade em Pesquisa do CNPq.

${ }^{3}$ M.Sc. Professor do Departamento de Agronomia, CAV/UDESC, Lages-SC. E-mail: a2prk@cav.udesc.br

${ }^{4}$ Acadêmicos do Curso de Agronomia, CAV/UDESC, Lages-SC. E-mail: a6jmb@cav.udesc.br; a6tam@cav.udesc.br. Bolsistas de Iniciação Científica do CNPq. 
A produção de pequenas frutas no Brasil vem sendo difundida pelas entidades de pesquisa e extensão, visando ao desenvolvimento de novas atividades agrícolas ligadas à fruticultura, principalmente em pequenas propriedades. O cultivo da framboesa (Rubus idaeus L.), no Brasil, está praticamente restrito às regiões sul e sudeste do País, uma vez que a cultura necessita de elevada quantidade de horas de frio para seu desenvolvimento (HOFFMANN;PAGOT, 2003); (RASEIRA et al., 2004). O Estado de Santa Catarina caracteriza-se por ter clima favorável ao cultivo de framboesa, porém há necessidade de caracterizar cultivares adaptadas às diferentes condições edafoclimáticas das regiões do Estado catarinense.

A produtividade da framboesa pode ser afetada em virtude de a espécie ser sensível ao excesso de chuvas e predomínio de alta umidade relativa do ar (HOFFMANN; PAGOT, 2003). Tal fato pode levar à ocorrência de doenças, como a ferrugem, constatada no Brasil pela primeira vez no município de Ibiúna-SP (FIGUEIREDO et al., 2003). De acordo com o Herbário Arthur da Universidade de Purdue, e com registros da Coleção Nacional de Fungos do Departamento de Agricultura dos Estados Unidos, apud. Figueiredo et al. (2003), o fungo já havia sido detectado no continente sul-americano, no Chile, em 1992, e na Colômbia, em 1993. Na Argentina, foi detectado pela primeira vez em 2003, nas províncias de Buenos Aires, Córdoba e Entre Ríos (LUCERO et al., 2008).

O agente causal da ferrugem da framboesa é o fungo Pucciniastrum americanum (Farl.) Arthur (DODGE, 1923; ARTHUR, 1962; LAUNDON; RAINBOW, 1969). É uma ferrugem heteroécia (CUMMINS;HIRATSUKA, 1983), considerada nativa do Canadá e dos Estados Unidos (ARTHUR, 1962). Este fungo apresenta urediniósporos elipsoides a obovoides e medem 10-18 x 15-26 $\mu \mathrm{m}$ (ARTHUR, 1962; LAUNDON; RAINBOW, 1969).

O presente trabalho teve como objetivo caracterizar a ocorrência de ferrugem em folhas e frutos de framboesa coletados de plantas do pomar de pequenos frutos do Centro de Ciências Agroveterinárias, Universidade do Estado de Santa Catarina, CAV-UDESC, localizado no município de Lages-SC.

Folhas e frutos de framboesa da cultivar Batum foram recebidos no dia 15 de abril de 2009, no Laboratório de Fitopatologia do CAV-UDESC (Registro $\mathrm{n}^{\circ} 22$ ), visando a caracterizar o agente causal da ferrugem. O material foi coletado de plantas que pertencem ao ensaio de adaptação de cultivares do pomar do CAV-UDESC. Foi depositado no Herbário
LUSC (Herbário Lages da Universidade do Estado de Santa Catarina). O pomar está localizado no centro da instituição com latitude $27^{\circ} 47^{\prime} 20^{\prime \prime}$ sul e longitude $50^{\circ} 18^{\prime} 10^{\prime \prime}$ oeste e altitude de $906 \mathrm{~m}$ acima do nível do mar. O solo da área é do tipo Cambissolo Húmico Alumínico Léptico (EMBRAPA, 2009). O ensaio de framboesa foi conduzido no sistema cruz de Lorena invertida, com 20 plantas por metro linear (HILLS, 1981).

A diagnose indireta da ferrugem foi feita pela caracterização dos sintomas do material recebido no laboratório e em visita ao pomar. No pomar, também, procedeu-se análise de quantificação da doença. Foram marcados e contados, ao acaso, 50 folhas e frutos de framboesa. A intensidade nestes órgãos foi determinada pela incidência e severidade foliar. A severidade foi determinada pela área afetada e pela presença de necrose na face adaxial da folha, determinada por um único avaliador, uma vez que não se dispunha de escala diagramática para o patossistema.

Sob lupa estereoscópica, com magnitude de 40 vezes, constataram-se os urediniósporos que romperam a epiderme da folha na face abaxial, expondo a massa de esporos de cor amarela. Das folhas infectadas foram cortados discos de tecido vegetal de $0,8 \mathrm{~mm}$ de diâmetro, os quais foram inseridos em $100 \mathrm{~mL}$ de água esterilizada contendo adjuvante (1 gota de Tween 20), sendo agitados em vórtex por cinco minutos, visando a manter os esporos em suspensão. Desta suspensão, foram retiradas alíquotas de $40 \mu \mathrm{L}$ e depositadas em lâmina de vidro para análise em microscopia ótica. A mensuração dos urediniósporos foi quantificada no microscópio ótico, com magnitude de 40x, pela contagem de 100 esporos. Foram feitas quatro contagens, quantificando a largura e o comprimento dos urediniósporos. Também foi feita varredura nas alíquotas visando a detectar os extremos para tamanho dos esporos.

Uma suspensão de urediniósporos em água esterilizada foi pulverizada em folhas destacadas da mesma cultivar, mantidas por $24 \mathrm{~h}$ no escuro, em câmara úmida, a $20^{\circ} \mathrm{C}$. O material foi mantido incubado por dez dias mantendo a temperatura e alternando o fotoperíodo para $12 \mathrm{~h}$. Folhascontrole foram inoculadas com água esterilizada. A temperatura e o regime de luz foram os mesmos utilizados por Lucero et al. (2008). A suspensão de esporos foi obtida a partir da imersão de folhas infectadas em erlenmeyers contendo $300 \mathrm{~mL}$ de água estéril e Tween 20. A concentração final foi ajustada por diluição contando os esporos em hemocitômetro. Utilizou-se uma concentração de 
50.000 urediniósporos $\mathrm{mL}^{-1}$. Foram inoculadas 20 folhas. As folhas foram acondicionadas em caixas de acrílico tipo gerbox (duas folhas por caixa) contendo duas camadas de papel-filtro sob uma espuma de 5 $\mathrm{mm}$ de espessura umedecidas em água esterilizada, visando a manter umidade.

Folhas sintomáticas apresentaram necrose na face superior, com início evidente nos bordos e/ou entre as nervuras principais da folha (Figura 1A). Na face abaxial, foram formadas inúmeras pústulas produzindo uma massa de urediniósporos de cor amarela (Figura 1B). Frutos imaturos ou em formação e frutos maduros apresentaram esporulação do fungo na forma de massa amarela de urediniósporos (Figura 1C e D). No pomar, a intensidade da ferrugem nas folhas, no estádio de maturação dos frutos, atingiu incidência de $92 \%$ e severidade de $27 \%$, com um aspecto de queima das folhas (Figura 1E). Os sintomas e sinais observados nas folhas recebidas no laboratório e folhas das plantas no pomar são idênticos aos descritos para $P$. americanum (FIGUEIREDO et al., 2003). Com as folhas infectadas, foram obtidas exicatas que foram guardadas na coleção do laboratório.
As características morfológicas indicaram urediniósporos pequenos, oblongos ou elipsoides, com parede levemente ornamentada, de cor laranja-claro, medindo 16 × $24 \mu \mathrm{m}(12,5-17,5 \times$ $15,0-30,0 \mu \mathrm{m})$ (Figura 1F). Lucero et al. (2008) também obtiveram as mesmas dimensões médias $(16 \times 24 \mu \mathrm{m})$ e maior comprimento $(30,0 \mu \mathrm{m})$ dos uredioniósporos da ferrugem detectada na Argentina. Figueiredo et at. (2003), com material coletado em São Paulo, obtiveram medidas de largura mínima e comprimento máximo um pouco inferiores (10-18 $\mathrm{x} 15-26 \mu \mathrm{m}$ ) aos obtidos neste trabalho. Os mesmos autores relataram coloração amarela para o conteúdo dos esporos, diferindo da cor laranja obtida neste trabalho. Não foram encontrados télios do fungo.

Após 12 dias de incubação das folhas destacadas, verificaram-se as urédias contendo urediniósporos na face abaxial das folhas pulverizadas com a suspensão de esporos. Não ocorreu ferrugem nas folhas inoculadas com água.

Com base nas características morfológicas e na mensuração dos urediniósporos, sintomas e sinais caracterizados no campo e pelo teste de patogenicidade, comparadas com informações descritas na literatura, conclui-se que a ferrugem detectada na cultivar Batum é causada pelo fungo Pucciniastrum americanum (Farl.) Arthur, sendo o primeiro relato no Estado de Santa Catarina. 

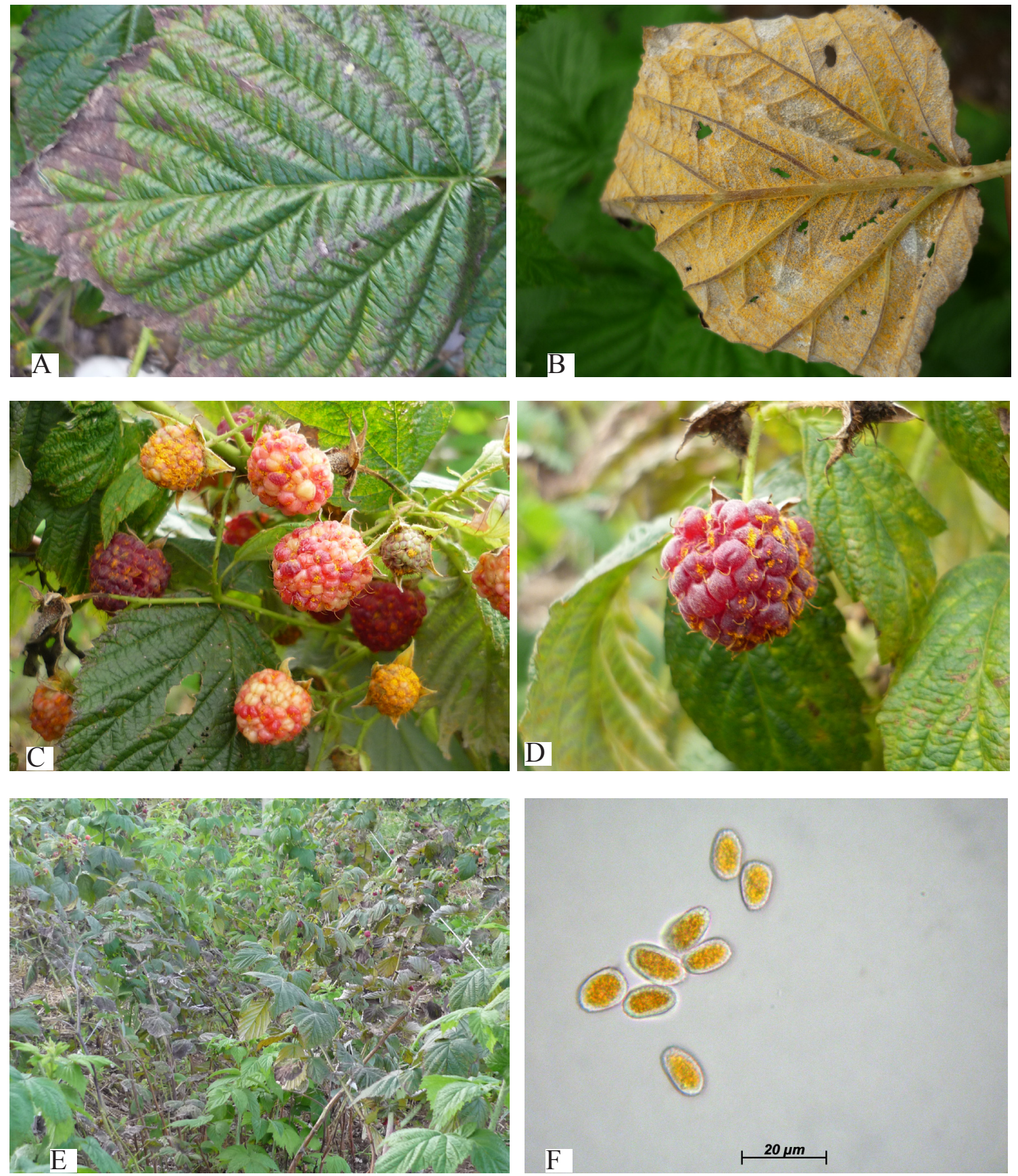

FIGURA 1- Ferrugem da framboesa: A. Sintoma de necrose em folhas; B. Esporulação do fungo na face adaxial da folha; C e D. Esporulação em frutos; E. Sintoma de queima das folhas em plantas no pomar; F. Uredósporos de Pucciniastrum americanum observados ao microscópio óptico (ZEISS - Axiostar Plus) (aumento 100x), fotografado em câmara digital PowerShot A640, 10 mega pixels. 


\section{REFERÊNCIAS}

ARTHUR, J.C. Manual of the rusts in United States and Canada. New York: Hafner, 1962. 438p.

CUMMINS, G.B.; HIRATSUKA, Y. Illustrated genera of rust fungi. St. Paul: The American Phytophatological Society, 1983. 152p.

DODGE, O. Morphology and host reactions of Pucciniastrum americanum. Journal Agricultural Research, Punjab, v.24, p.885-894, 1923.

EMBRAPA. Sistema brasileiro de classificação de solos. Disponível em: <www.cnps.embrapa.br/ sibcs/>. Acesso em: 10 abr. 2009.

FIGUEIREDO, M.B.; NOGUEIRA, E.M.C.; FERRARI, J.T.; APARECIDO, C.C.; HENNEN, J.F. Ocorrência de ferrugem em framboesa no Estado de São Paulo. Arquivo do Instituto Biológico, São Paulo, v.70, p.199-201, 2003.
HILLS, F.S. La Frambuesa. Santiago: Universidad de Chile, 1981. 111p. (Ciências Agrícolas, 8)

HOFFMAnN, A.; PAGOT, E. Produção de pequenas frutas no Brasil. In: I Seminário Brasileiro sobre Pequenas Frutas, 2003, Bento gonçalves. I Seminário Brasileiro sobre Pequenas Frutas, 2003. v.1. p.9-17.

LAUNDON, G.F.; RAINBOW, A.F. Pucciniastrum americanum. IMI Descriptions of Fungi and Bacteria, Surrey, n.210, p.1-2, 1969.

LUCERO, X.; WRIGHT, E.R.; PÉREZ, B.A. Occurrence of late leaf rust caused by Pucciniastrum americanum in red raspberry (Rubus idaeus) in Buenos Aires, Córdoba, and Entre Ríos, Argentina. Plant Disease, St. Paul, v.92, p.653, 2008.

RASEIRA, M.C.B.; GONÇALVES, E.D.G.; TREVISAN, R.; ANTUNES, L.E.C. Aspectos técnicos da cultura da framboeseira. Pelotas: Embrapa Clima Temperado, 2004. 22 p. (Embrapa Clima Temperado. Documentos, 120). 